\title{
Porous Biomass Carbon Derived from Peanut Shells as Electrode Materials with Enhanced Electrochemical Performance for Supercapacitors
}

\author{
Zuoan Xiao ${ }^{1}$, Wenwen Chen $^{1}$, Ke Liu $^{2}$, Ping Cui ${ }^{1}$, Dan Zhan ${ }^{1,2, *}$ \\ ${ }^{1}$ Department of Chemical Engineering, Hubei University of Arts and Science, Xiangyang, 441053, P. \\ R. China \\ ${ }^{2}$ Hubei Key Laboratory of Low Dimensional Optoelectronic Materials and Devices, Xiangyang, \\ 441053, P. R. China \\ *E-mail: dan_zhan@126.com
}

doi: $10.20964 / 2018.06 .54$

Received: 8 February 2018 / Accepted: 30 March 2018 / Published: 10 May 2018

\begin{abstract}
A hierarchical porous carbon with high surface area derived from peanut shells was synthesized via a simple, valid and economical route involving hydrothermal treatment, $\mathrm{ZnCl}_{2}$ activation and pyrolysis. The products were characterized by XRD, SEM, Raman and Brunauer Emmett-Teller (BET) tests. The electrochemical performance was explored by cyclic voltammetry, galvanostatic charge-discharge and electrochemical impedance measurements. It was found that the peanut shell-derived carbon electrode materials in supercapacitors exhibited high capacitance $\left(340 \mathrm{~F} \mathrm{~g} \mathrm{~g}^{-1}\right)$, excellent rate performance $(54.7 \%$ capacitance retention from $0.25 \mathrm{~A} \mathrm{~g}^{-1}$ to $50 \mathrm{~A} \mathrm{~g}^{-1}$ ) and outstanding cycle stability (capacitance decay of $4.7 \%$ after 10000 cycles at $1 \mathrm{~A} \mathrm{~g}^{-1}$ ), which benefit from the unique hierarchical structure. The excellent electrochemical performance endows the peanut shell-derived carbon with promising prospects for high performance supercapacitors.
\end{abstract}

Keywords: peanut shell; porous carbon; $\mathrm{ZnCl}_{2}$ activation; supercapacitors; electrochemical performance.

\section{$\underline{\text { FULL TEXT }}$}

(C) 2018 The Authors. Published by ESG (www.electrochemsci.org). This article is an open access article distributed under the terms and conditions of the Creative Commons Attribution license (http://creativecommons.org/licenses/by/4.0/). 